\title{
Angiomyofibroblastoma of the Lower Genital Tract of Women: Report of Two Cases
}

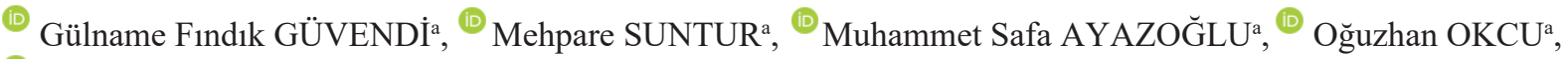 \\ (D) Recep BEDİR ${ }^{\mathrm{a}}$

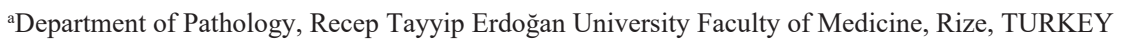

\begin{abstract}
Superficial angiomyofibroblastoma of the lower genital tract of women is a very rare, benign neoplasm that most commonly arises in the vulvo-vaginal area. Our first case is a 45-year-old woman who presented with menometrorrhagia. On gynecological examination, a pedinculated polipoid mass $2.5 \mathrm{~cm}$ in size was found on the cervix. The second case is a 40 -year-old woman presented with a nodular mass $5 \mathrm{~cm}$ in size on the vulva. She admitted to hospital with itching and cosmetic problems. Histologic examination revealed bland spindled and epithelioid cells arranged around blood vessels. Tumor cells have immunoreactivity for desmin, vimentin, estrogen and progesterone receptors but staining for cytokeratin was negative. In the lipomatous variant, the cells are dispersed into the adipose tissue. Differential diagnosis of lipomatous angiomyofibroblastoma includes; spindle cell lipoma, angiomyolipoma, and cellular angiofibroma. We will discuss the differential diagnosis of these cases with immunohistochemical and morphological findings.
\end{abstract}

Keywords: Superficial angiomyofibroblastoma; uterine cervix; vulva

Superficial angiomyofibroblastoma of the genital tract (SAMFGT) typically arises from the subepithelial stromal cells of the vagina, less commonly from the vulva and cervix. ${ }^{1}$ Only one case with superficial angiomyofibroblastoma (SAMFB) in the ovary has been described in the literature. ${ }^{2}$ Also a case of pregnant woman presented with a mass prolapsed from the vagina has been reported, and this is the first case of (SAMFGT) occurring in a pregnant woman. Clinically, these tumors are often confused with Bartholin's gland cysts, because of their slowly growing nature and the formation of pedunculated mass on the vulva. ${ }^{3,4}$ Although SAMFB is known as a rare mesenchymal neoplasm presented in the lower genital tract of middle-aged women, mostly on the vulva, four cases of SAMFB-like tumors have been reported in the scrotum, perineum, or spermatic cord in men. ${ }^{4,5}$ The lipomatous variant is an extremely rare variant of this tumor and was first described by Laskin et al. ${ }^{6}$ There are only 16 cases of lipomatous variant of angiomyofibroblastoma have been reported in the literature.

\section{CASE REPORT}

\section{CASE 1}

A 45-year-old woman was admitted to hospital with abnormal uterine bleeding. On general examination, a pedunculated mass $2.5 \mathrm{~cm}$ in size was seen on the cervix. The mass was excised and endometrial curettage was also performed due to abnormal uterine bleeding.The specimen was firm, smooth, pedunculated, polipoid mass $2.5 \times 2 \times 1 \mathrm{~cm}$ in size. The cut surface was solid and gray-white in color (Figure 1A). There was no necrosis or hemorrhage. The tumor was encapsulated. Microscopic examination of the polipoid mass revealed ovoid, stellate and spindled cells located around the vessels and embedded in collagenized, hyalinized, and vascularized stroma (Figure 1B, Figure

Correspondence: Recep BEDIR

Department of Pathology, Recep Tayyip Erdoğan University Faculty of Medicine, Rize, TURKEY

E-mail: bedirrecep@gmail.com

Peer review under responsibility of Journal of Clinical Obstetrics \& Gynecology.

Received: 11 Dec $2020 \quad$ Accepted: 04 Mar $2021 \quad$ Available online: 05 Mar 2021
2619-9467 / Copyright @ 2021 by Türkiye Klinikleri. This is an open
access article under the CC BY-NC-ND license (http://creativecommons.org/licenses/by-nc-nd/4.0/).



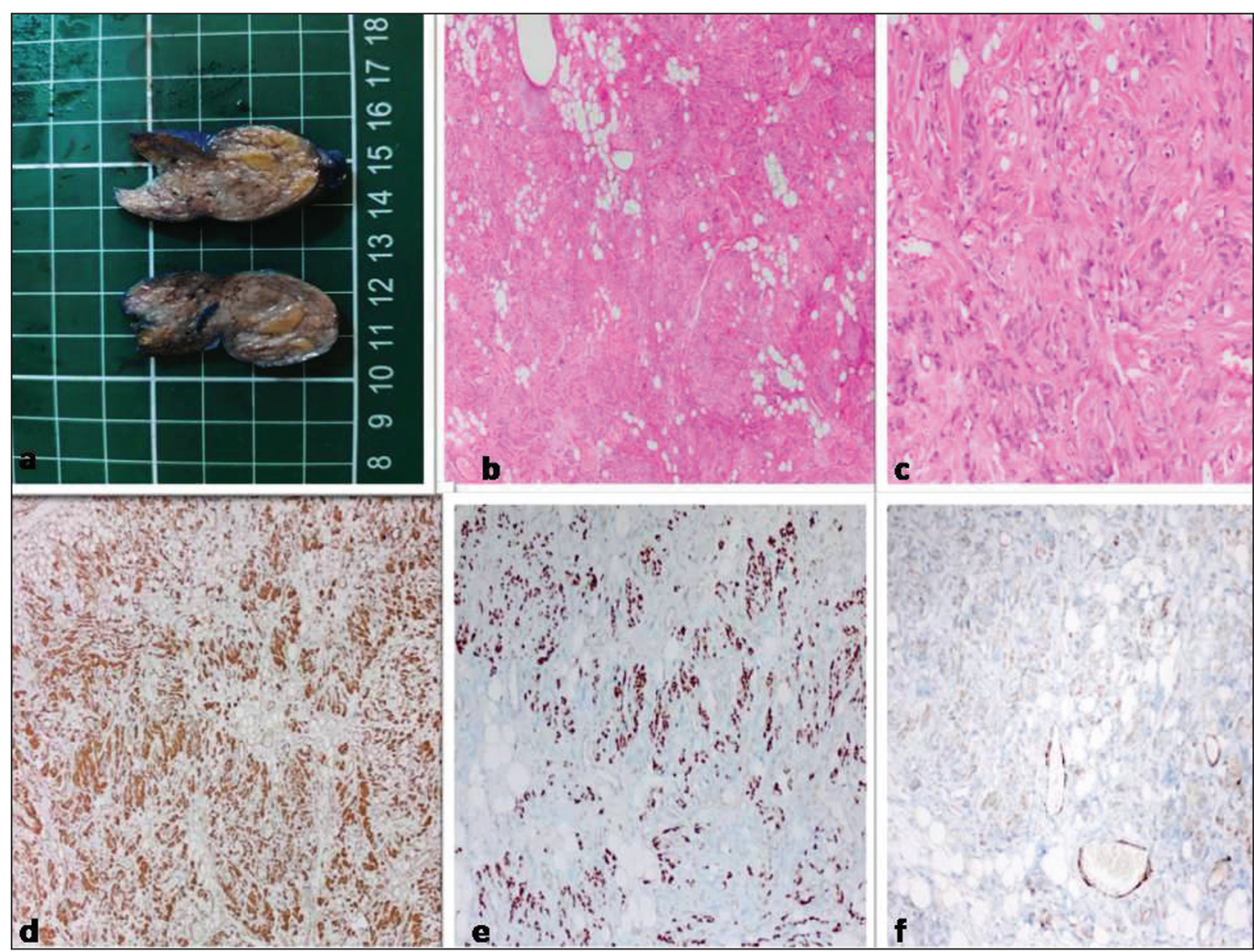

FIGURE 1: A) Macroscopic examination showing firm, smooth, pedunculated, polipoid mass on a broad stalk, attached to the cervix. B-C) Neoplasm composed of relatively hypocellular ovoid, stellate to spindle-shaped cells in a patternless distribution in an edematous to myxoid, variably collagenized and vascularized stroma (H\&Ex100 and H\&Ex400). D) Tumor showing strong positivity for vimentin (x400). E) Tumor showing strong positivity for desmin (x400). F) Tumor showing positivity for CD34 (x400).

1C). There was no mitotic activity or necrosis. The immunohistochemical examination revealed strong expression with desmin, vimentin, CD34 and estrogen receptor (ER) (Figure 1D, Figure 1E, Figure 1F). The proliferation index of $\mathrm{Ki}-67$ of the neoplasm was low. Based on these findings, it was reported as SAMFGT. Written informed consent was obtained from the patient for publication of this case report.

\section{CASE 2}

A 40-year-old woman presented with hypermenorrhea, leukorrhea, itching, and had a normally localized intrauterin device (IUD). IUD was removed because of candida and trichomonas infection. On ultrasonographic examination, a solid vascularized mass $5 \times 3 \mathrm{~cm}$ in size was found and excised. Macroscopically, the mass was a well-circumscribed, brown-yellow in color, $5.5 \times 4.5 \times 2.2 \mathrm{~cm}$ in size. The cut surface was yellow and had myxoid areas (Figure 2A). Microscopic examination revealed that approximately
$40-50 \%$ of the lesion was composed of mature adipose tissue in a lobulated fashion. The neoplastic cells were spindled and epithelioid, and arranged around vessels. The stroma was myxoid and fibrous in some areas (Figure 2B, Figure 2C). No mitotic activity, necrosis, or atypia was seen. Immunohistochemically, the spindled and epithelioid cells were positive for ER, vimentin, desmin and CD34 while negative for smooth muscle actin (SMA) (Figure 2D, Figure 2E, Figure 2F). The proliferation index of Ki-67 of the neoplasm was $1-2 \%$. Based on these findings, it was reported as lipomatous variant of SAMFGT. Written informed consent was obtained from the patient for publication of this case report.

\section{DISCUSSION}

SAMFGT is a benign mesenchymal tumor and can be confused with many lesions in that location. Cervical leiomyoma, Nabothian cysts, cervical cancers, and other rare tumors of the cervix should be considered 


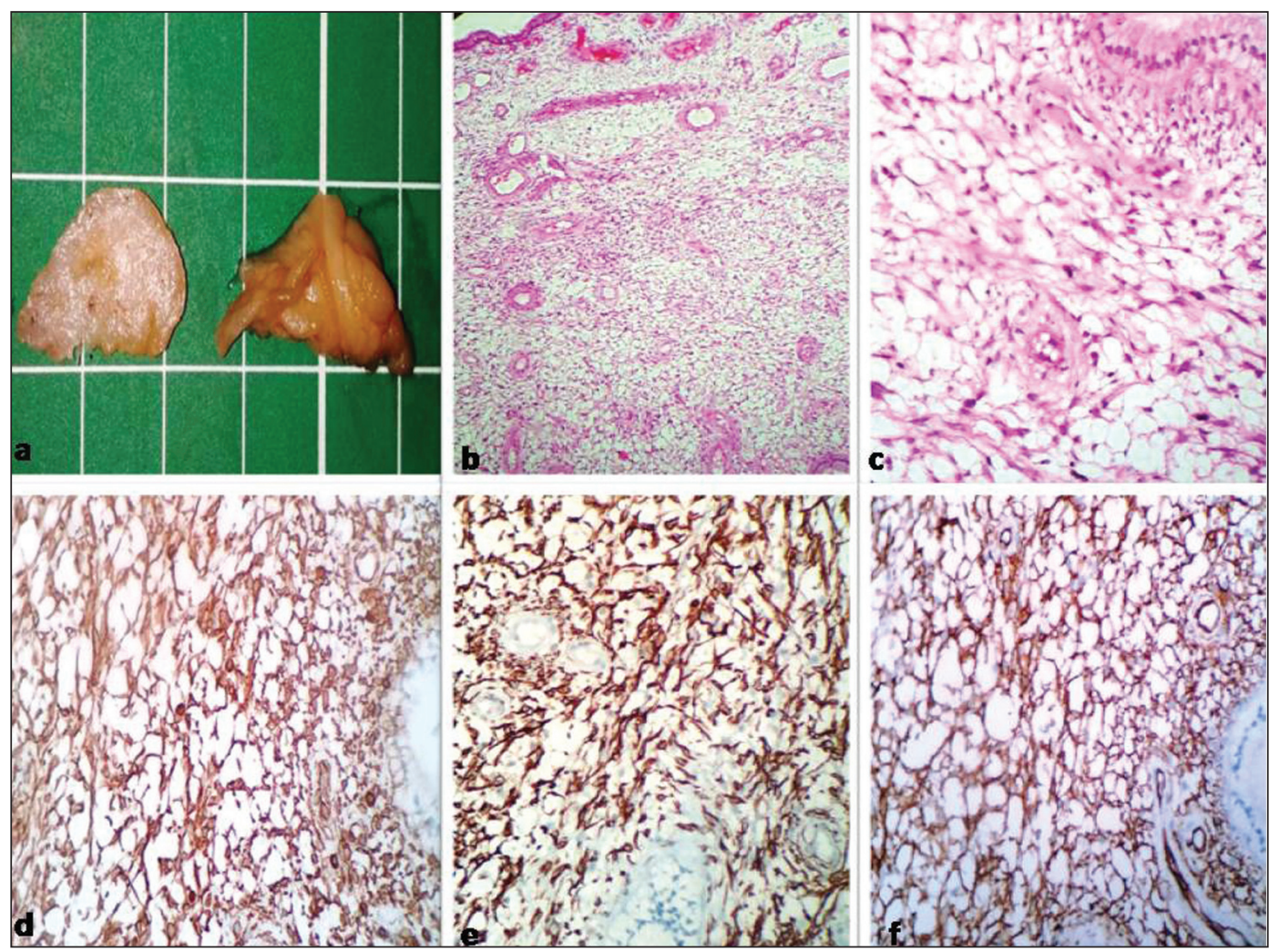

FIGURE 2: A) Macroscopic examination showing a well-circumscribed, solid mass and brown-yellow in color. B-C) Neoplasm composed of relatively hypocellular ovoid, stellate to spindle-shaped cells in a patternless distribution in an edematous to myxoid, variably collagenized, lipomatous and vascularized stroma (H\&Ex100 and $\mathrm{H} \&$ Ex400). D) Tumor showing strong positivity for vimentin (x400). E) Tumor showing strong positivity for estrogen receptor (x400). F) Tumor showing strong positivity for CD34 (x400).

in differential diagnosis. SAMFGT is easier to distinguish from Nabothian cysts because of its solid structure. SAMFGT has a tendency to be more well-circumscribed and nodular compared to cervical cancers which shows extensive mucosal irregularities. A differential diagnosis can be made by performing colposcopic biopsy. Leiomyoma is a benign smooth muscle tumor and can easily be diagnosed histomorphologically. Although differential diagnosis is difficult in leiomyomas with degenerative myxoid changes, leiomyoma is predominantly composed of smooth muscle and can easily be distinguished from SAMFGT. In aggressive angiomyxoma (AAG), the myxoid areas are seen with predominance compared to SAMFGT which is composed of prominent epithelioid cells around the vessels. In addition, AAG may invade the adipose tissue, muscles, and nerves. ${ }^{1,7,8}$

Vulvar SAMFGT is described as a sharply demarcated, slowly-growing, painless, rubbery mass ranging in size from 0.5 to $12 \mathrm{~cm}$ in the literature. Clinically, these tumors may be misdiagnosed as
Bartholin's gland cysts, inguinal hernia, leiomyoma or mesenchymal tumors such as lipoma and liposarcoma. ${ }^{3,9}$ Microscopic examination reveals a well-defined tumor composed of admixture of hyper- and hypocellular edematous stromal areas rich in vascular structure. Nuclear atypia or mitotic figures were rare and tumor cells tend to cluster around blood vessels. ${ }^{3,10}$ Sometimes adipocytes may be scattered throughout the mass and these tumors have been classified as a "lipomatous" variant of SAMFB. Lipomatous angiomyofibroblastoma (LAMFB), on the other hand, has been reported as a rare variant of SAMFB with a mature adipose tissue component. All of the reported LAMFB were tumors on the vulva ranging in size from 1.1 to $12 \mathrm{~cm}$. The mean age of the patients was 42 years. Microscopic examination revealed hypocellular and hypercellular areas composed of spindle and epithelioid cells within the vascular stroma. Mitotic activity was low and no necrosis or atypia was seen. In the majority of cases, mature adipose tissue accounted for about $30 \%$ to 
$90 \%$ of the tumor. ${ }^{10}$ The source of adipose tissue in vulvo-vaginal LAMFB is not clear. There is no consensus on the amount of lipomatous component required for tissue diagnosis of LAMFB. The main differential diagnoses of LAMFB are various lipomatous neoplasms, including liposarcoma, angiolipoma, pleomorphic lipoma and spindle cell lipoma, and other mesenchymal lesions that may contain a cellular lipomatous component. Lipomatous tumors are rare in the vulva and vagina. When examining a lipomatous neoplasm in this area, especially if the lesion is large, the pathologist should carefully sample the specimen to exclude LAMFB. Positive staining with ER can be helpful, since lipomatous neoplasms are expected to be negative for ER. In liposarcoma, nuclei are more hyperchromatic. Floret-like giant cells should be observed in pleomorphic/spindle cell lipoma. ${ }^{8-10}$ Superficial angiomyxoma (cutaneous myxoma) is generally superficial, small-sized $(0.5 \mathrm{~cm})$, well-circumscribed tumor and has mucoid content. Microscopic examination reveals few stellate cells in the abundant myxoid stroma. Cellular angiofibroma is seen in the superficial portion of the vulva and less commonly seen in the vagina, perineum, urethra or groin area. Macroscopically, these lesions are well-circumscribed and gray-white in color. Microscopically, they are composed of spindle cells and thick-walled, often hyalinized vessels. Immunoreactivity with CD34, desmin and SMA is more common. ${ }^{1-3}$ Spindle cell lipoma of the vulva and well differentiated liposarcoma are also very rare. Although the morphology is similar in spindle cell lipoma, hormone receptors expected to be negative in spindle cell lipoma. Differentiating LAMFB from well-differentiated liposarcoma can be made with histomorphological examination as well as loss of expression with MDM2 and S100.9,10

In conclusion, SAMFGT, LAMFB in the lower genital tract of women are very rare neoplasms. It should be kept in mind by pathologists and clinicians, since this lesion can be confused clinically and morphologically with other more common tumors in the same localization. As, this is a benign tumor, accurate diagnosis is extremely important to avoid aggressive treatment.

\section{Source of Finance}

During this study, no financial or spiritual support was received neither from any pharmaceutical company that has a direct connection with the research subject, nor from a company that provides or produces medical instruments and materials which may negatively affect the evaluation process of this study.

\section{Conflict of Interest}

No conflicts of interest between the authors and / or family members of the scientific and medical committee members or members of the potential conflicts of interest, counseling, expertise, working conditions, share holding and similar situations in any firm.

\section{Authorship Contributions}

Idea/Concept: Recep Bedir, Gülname Findık Güvendi; Design: Recep Bedir, Gülname Findlk Güvendi; Control/Supervision: Recep Bedir; Data Collection and/or Processing: Recep Bedir, Mehpare Suntur, Safa Ayazoğlu, Oğuzhan Okçu, Gülname Fındık Güvendi; Analysis and/or Interpretation: Recep Bedir, Gülname Findlk Güvendi; Literature Review: Recep Bedir, Gülname Fındık Güvendi; Writing the Article: Gülname Findlk Güvendi, Recep Bedir; Critical Review: Recep Bedir.

\section{REFERENCES}

1. Abdelaziz M, Eziba N, Sharma S, Kleven D, AlHendy A. Cervical superficial myofibroblastoma: case report and review of the literature. SAGE Open Med Case Rep. 2017;4;5:2050313X17726936. [Crossref] [PubMed] [PMC]

2. Adams B, Fogarty P, McKenna M, McManus D. Superficial myofibroblastoma of the lower female genital tract: first case report of a pregnant patient. J Obstet Gynaecol. 2008;28(6):657-8. [Crossref] [PubMed]

3. Seo JW, Lee KA, Yoon NR, Lee JW, Kim BG, Bae DS. Angiomyofibroblastoma of the vulva. Obstet Gynecol Sci. 2013;56(5):349-51. [Crossref] [PubMed] [PMC]

4. Omori M, Toyoda H, Hirai T, Ogino T, Okada S. Angiomyofibroblastoma of the vulva: a large peduncu- lated mass formation. Acta Med Okayama 2006;60(4):237-42. [PubMed]

5. Giannella L, Costantini M, Mfuta K, Cavazza A, Cerami $L B$, Gardini $G$, et al. Pedunculated angiomyofibroblastoma of the vulva: case report and review of the literature. Case Rep Med. 2011;2011:893261. [Crossref] [PubMed] [PMC]

6. Matsukuma S, Koga A, Suematsu R, Takeo H, Sato $\mathrm{K}$. Lipomatous angiomyofibroblastoma of the vulva: a case report and review of the literature. Mol Clin Oncol. 2017;6(1):83-7. [Crossref] [PubMed] [PMC]

7. Cinel L, Taner D, Nabaei SM, Dogan M. Aggressive angiomyxoma of the vagina. Report of a distinctive type gynecologic soft tissue neoplasm. Acta Obstet Gynecol
Scand. 2000;79(3):232-3. [Crossref] [PubMed]

8. Granter SR, Nucci MR, Fletcher CD. Aggressive angiomyxoma: reappraisal of its relationship to angiomyofibroblastoma in a series of 16 cases. Histopathology. 1997;30(1):3-10. [Crossref] [PubMed]

9. Tochika N, Takeshita A, Sonobe H, Matsumoto M, Kobayashi M, Araki K. Angiomyofibroblastoma of the vulva: report of a case. Surg Today. 2001;31(6):5579. [Crossref] [PubMed]

10. Nielsen GP, Young RH. Mesenchymal tumors and tumor-like lesions of the female genital tract: a selective review with emphasis on recently described entities. Int J Gynecol Pathol. 2001;20(2):105-27. [Crossref] [PubMed] 